\title{
Fuel Saving in Coal Fired Thermal Power Plant by using Solar Heated Feed Water
}

\author{
${ }^{1}$ Parvati P, \\ Student, TCE Gadag,
}

\author{
${ }^{2}$ Roopashree M, \\ Student, TCE Gadag,
}

\author{
${ }^{3}$ Santhoshkumar G.M, \\ Assistant Professor EEE Dept, \\ TCE gadag.
}

\begin{abstract}
There are various ways to generate electricity. The major source of electricity generation is by coal fired thermal power plants, which is non renewable source energy. And also these power plants release harmful substances to the environment such as carbon dioxide, carbon monoxide, nitrogen oxide, etc. in such power plants we are going to fix concentrating solar collector to which will absorb the maximum solar radiation and preheat the water before feeding in to the boiler tank. This will reduce the amount of coal burning and also increases the efficiency of power plant.
\end{abstract}

\section{INTRODUCTION}

Electricity generation plays an important role in this world. Now-a-days life fully dependent of electricity, All the equipments or machineries which we are using daily run on electricity. Electricity generation plays very important role in the economic development of the country. As the energy demand is increasing now-a-days with rapid growth in industrialization as well as modernization. But energy resources are gradually depleting to high extent.

The availability of fossil fuels such as coal, oil and natural gas are diminishing day by day and the demand for power is also increasing. It became very difficult to meet the load demand especially in developing countries. According to the world energy consumption data coal is the most used fuel to harness electricity at about $27 \%$ [2018 data]. Institutions such as, International Energy Agency (IEA), the US. Energy Information Administration (EIA), and the European Environment Agency (EEA) record and publish energy data periodically. In present time availability of fossil fuels are decreased and on other hand renewable energy resources such as solar, wind, tidal, etc, are abundantly available in nature with free of cost. So it is more beneficial to use these renewable energies more instead of fossil fuels or together with fossil fuels.

Solar thermal power is a finest prospective renewable energy resource. Still many nations trust on conventional energy sources and nuclear fuels to generate electrical power. However interest in renewable energy sources is growing through common people about the negative effect of burning fossil fuels on the environment. Electricity generation is becoming increasingly costly and environment pollution is the big issue. [1]

In this project we proposed a modification to integrate solar energy with our existing thermal power station to save the fuel which will also help in global climate change by reducing greenhouse gas $\left(\mathrm{CO}_{2}\right)$ emission coming from the coal fired power plants. In addition boiler efficiency typically increases slightly as boiler load is reduced.

\section{OBJECTIVE}

A. The main objective of this project work is, by using concentrating solar collector preheating the water before feeding it to the boiler is,

- Implementing solar augmentation to already existing thermal power plant reduces coal burning.

- To produce electricity with a reduced running coast and less emission of greenhouse gases such as $\mathrm{CO}_{2}$, $\mathrm{NO}_{\mathrm{X}}$ and $\mathrm{SO}_{2}$.

\section{BLOCK DIAGRAM}

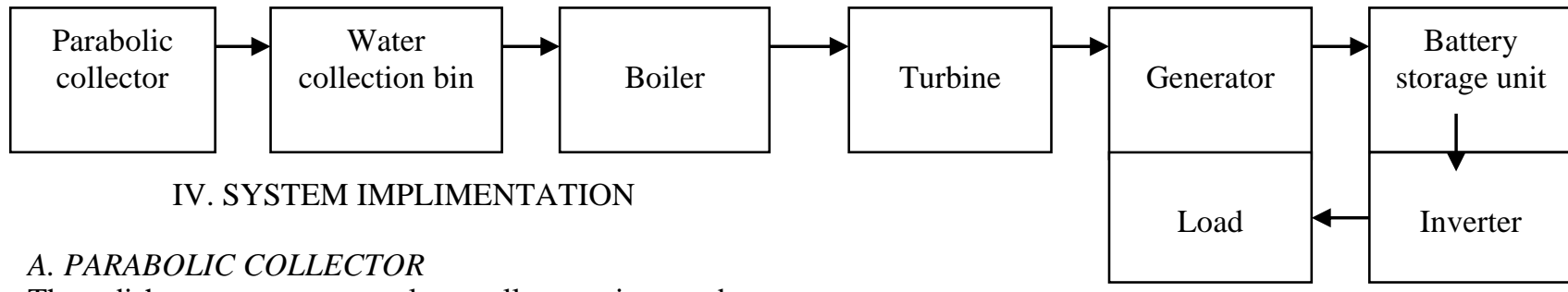

The dish concentrater solar collector is used to concentrate the solar energy at a single focal point, similar to the way a reflecting telescope focuses star light or a dish antenna focuses radio waves. This geometry may be used in solar furnaces and solar power plants. The shape of a parabola designed such that incoming light rays which are parallel to the dish's axis will be reflected toward the focus, no matter where on the dish they arrive. Light from the sun arrives at the Earth's surface almost completely parallel, and dish is aligned with its axis pointing at the sun, allowing almost all incoming radiation to be reflected towards the focal point of the dish. 


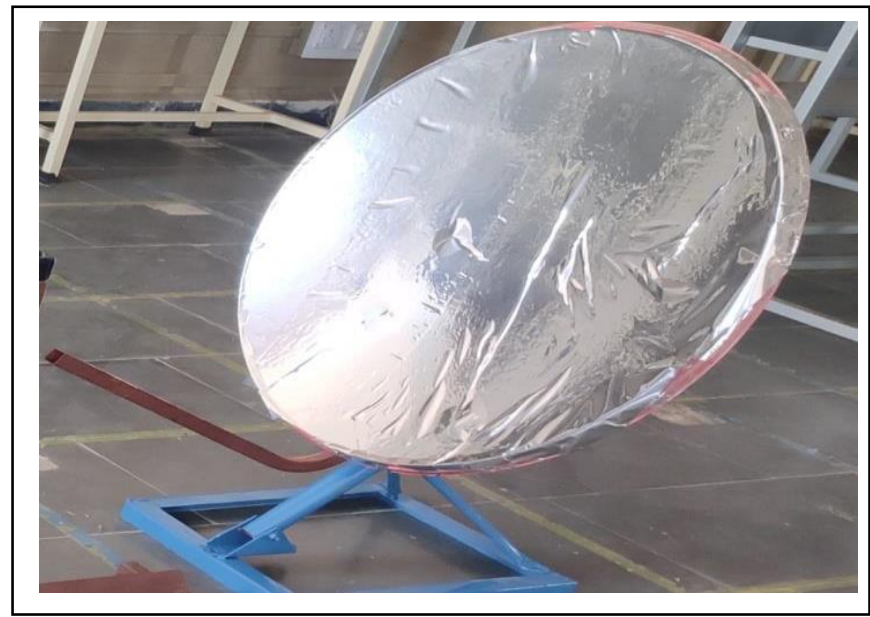

Figure 1 Parabolic solar collector

The offset design of this parabolic solar collector has a single strong feed support at the bottom. The outline shape is not exactly about $30^{\circ}$ when the front face of the dish is vertical. The advantage of this design is that the feed itself does not obstruct the beam.

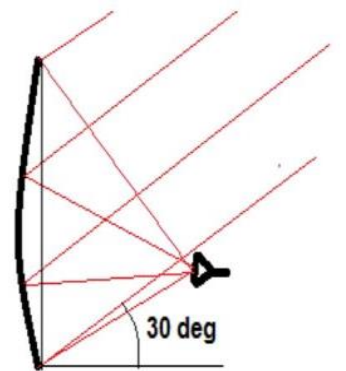

(a)

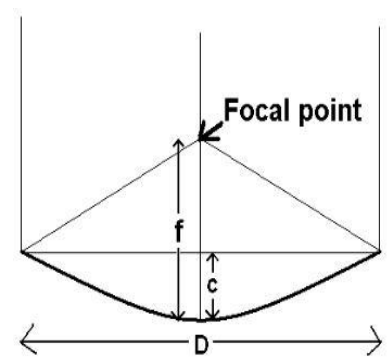

(b)
Figure 2 (a) and (b) shows the $30^{\circ}$ offset design and parabolic dish showing measurements needed to determine the focal length.

If the f/D ratio is low, say 0.25 to 0.35 then the feed will be close to the dish and needs to spread its power at a wide angle to efficiency illuminate the dish. The feed therefore needs to be small diameter. If the f/D is 0.25 the feed is level with the dish aperture, which may make it difficult to make a satisfactory feed. If the f/D is large like 0.5 to 0.75 then the feed be further away from the dish and needs to project its power into a narrower angle. The feed needs to be of larger diameter.

A solar concentrator parabolic dish and the temperature available at the focal point is close to $140^{\circ} \mathrm{C}$. if a parabolic dish of larger size is used and the focal point is well insulated then temperature in the range of $300^{\circ} \mathrm{C}$ could be achieved. The efficiency of concentrating solar power system will depend on the technology used to convert the solar power to heat energy, the operating temperature of the receiver and the heat rejection, thermal losses in the system, and the presence or absence of the other system losses; in addition to the conversion efficiency, the optical system which concentrate the sunlight will also add additional losses.

Real-world systems claim a maximum conversion efficiency of $23-24 \%$ for "power tower" type systems, operating at temperatures from $250-565^{\circ} \mathrm{C}$, with the higher efficiency. Dish Stirling systems, operating at temperatures of $550-750^{\circ} \mathrm{C}$, claim an efficiency of about $30 \%$. Due to variation in sun incidence during the day, the average conversion efficiency achieved is not equal to these maximum efficiencies, and the net annual solar-to-electricity.

\section{B. BOILER TANK AND PRESSURE GAUGE}

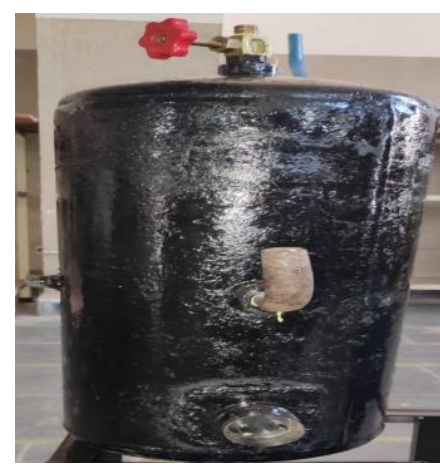

(a)

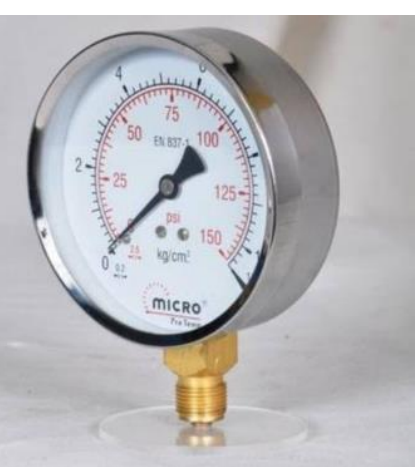

(b)
Figure 3 Boiler tank and pressure gauge

Boiler tank is also called as steam generator. It is used to create steam by applying heat to the water. In actual thermal power plant boiler tank is heated by furnace inside the boiler. In the proposed system 1000 watt heater coil is fixed to heat the water. The boiler tank capacity is about 10-15 litres. Boiler dimensions are, diameter 10", height-30", wall thickness- $8 \mathrm{~mm}$. inlet pipe diameter is $6 \mathrm{~mm}$; outlet pipe diameter is $5 \mathrm{~mm}$. The tank material used here is MS 12 gauge.

Pressure gauge is a instrument used for measuring the condition of fluid that specified by the force that fluid exert. [1] The measuring of the pressure gauge used in the project is $0-700 \mathrm{KG} / \mathrm{cm}^{2}$, the accuracy is $+/-2 \%$. The socket used is of Brass, the window is of plain glass. The pointer is of Aluminum black adjustable pointer.

The pressure gauge used in the project is commercial type pressure gauge. Because of the high reliability range of pressure gauge is chiefly attributed to the unique pressure gauge ring Suspended Movement. The entire movement is suspended between the springs, the Burdon tube above and link below. Wearing parts have been reduced to minimum. [3]

\section{TURBINE AND DC GENERATOR}

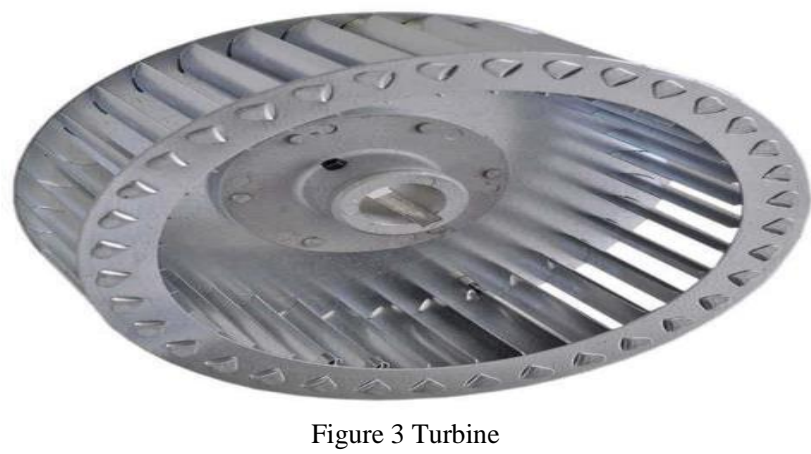


Turbine is picked up by rotary mechanical device which extracts energy from fluid flows and converts it into useful work. It works on simple principle the energy from fluids flows turns the three propeller like blades around the rotor which is connected to the main shaft that spin the generator which produces electricity.[5] the turbine used in the project is impeller turbine an impeller turbine is used due to cost efficiency and demonstration purpose. The diameter of the turbine is of 15 inches. It is having single/double inlet and clockwise/anticlockwise rotation. Hub bore sizes are of $1 / 4$ inches. The turbine is made up of Galvanized Steel, Aluminum, and Aluminum steel.

The motor type used in the proposed system is permanent magnet brushed motor. The rated voltage of DC generator is $12 \mathrm{~V}$ DC. The no load current is 0.2 Amps ( Max 1.2Amps). The no load speed is 1000 RPM. The motor shaft diameter is $3.17 \mathrm{~mm}$.

\section{BATTERY AND INVERTER}

In the project $12 \mathrm{~V}$ rechargeable lead acid battery is used to store the electrical energy produced. A $12 \mathrm{~V}$ battery has six single cells in series producing a fully charged output voltage of 12.6 of lead dioxide and negative made of sponge lead, with an insulating material (separator) in between.

Inverter is a device that converts direct current to alternating current to alternating current. As the output of the generator is dc the inverter is used to convert direct current to alternating current.

\section{WORKING OF THE SYSTEM}

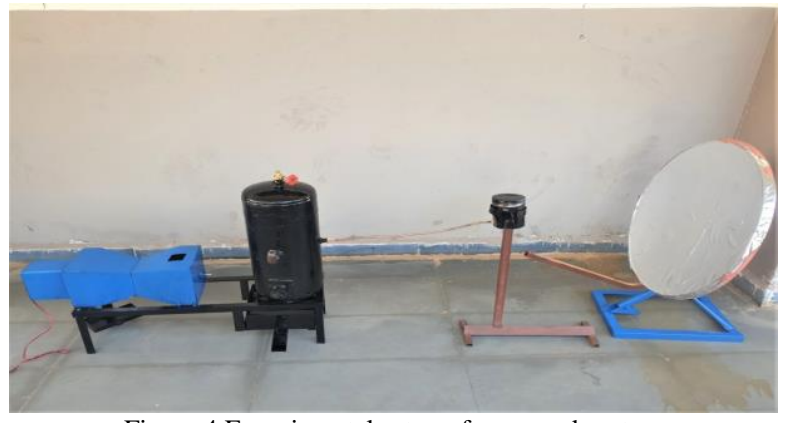

Figure 4 Experimental setup of proposed system

The parabolic solar collector absorbs the maximum solar by fixing it with a high absorbing focal point. It reflects the high solar radiations to the water collection bin. The water in the collection bin will be heated at its maximum by the reflected rays of parabolic solar collector.

The preheated water is given to the boiler for further heating. The hot water is converted into steam in the boiler. The high pressure steam is feed to the turbine. The turbine is coupled to the generator to generate electricity. The output obtained from the generator is AC. The battery storage unit stores the generated energy. The generated electricity is converted into DC by using inverter circuit. The output of inverter circuit is connected to load. By this technique the coal burning can be effectively reduced.

\section{ADVANTAGES AND DISADVANTAGES}

\section{ADVANTAGES}

- The fuel saving takes place when HP and LP replaced by solar field is of 25 to 26 ton coal $/ \mathrm{hr}$ respectively.

- This approach will reduce the running cost of solar thermal power plants.

- It will boast the capacity of the plant.

- Integration of solar energy into the conventional coal-fired unit reduces $\mathrm{CO}_{2}, \mathrm{NO}_{\mathrm{X}}$ emissions.

\section{DISADVANTAGES}

- Initial cost of purchasing solar parabolic collectors is fairly high.

- Its weather dependent. Although solar energy can still be collected during cloudy and rainy days, but efficiency drops during these days.

\section{CONCLUSION}

The solar augmentation concept allows boosting the electric capacity output of the power plant up to 4-5 MW which represents almost about $1 \%$ increase of the total output of the 500MW power plant. His will also increase the Rankine Cycle efficiency. The economic analysis and augmented solar unit will reduce total fuel consumption in the boiler. Thus this will have huge impact on industry profitability. The integration of solar energy into the conventional coal-fired unit has great potential for the energy saving and mitigation of the greenhouse gas emissions. Especially with the pressure of $\mathrm{CO}_{2}$ emission reductions, the rising carbon tax and coal price, the solar energy integration will become good option for coal-fired power plants.

\section{ACKNOWLEGEMENT}

I would like to express my special gratitude to our guide Prof.Santoshkumar G.M as well as our Hod.Dr.Iranna Korachgao, who gave us a wonderful opportunity to do this project which helped us in doing a lot of research. And i also extend my thanks to our principle Dr. M.M.Awati, Tontadaraya College of Engineering Gadag.

\section{REFRENCES}

11] Vivek Patel, Balaram Saha, kalyan Chatterjee, "Fuel Saving in Coa Fired Thermal Power Plant by Agumetation of Solar Energy", 9781-4799-5912-9/14/\$31.00 2014 IEEE

[2] M.K Islam, M.M. Rahman, M. Hasanuzzaman, N.A. Rahim, UM Power Energy Dedicated Advanced Centre (UMPEDAC), Level 4 Wisma R\&D, University of Malaya, 59990 Kuala Lumpur, Malaysia, "Thermal Performance Improvement of Solar Thermal Power Generation".

[3] Alsharkawi*, J.A. Rossiter** Deparment of Automatic Control and System Engineering University of Sheffield, S1 3JD, UK, "Modelling Analysis of Solar Thermal Power Plant" Yuchen Fang Shuqiang Zhao, and Zhiwei Li State Key Laboratory of Alternate Electrical Power System with Renewable Energy Sources North Chine Electric Power University, Baoding, Hebei, China, "Concentrating Solar Power Station Optimal Operation Model" 2018 IEEE

[4] Arnab Dey, Bipul Nath, Biplab Mondal, Rajarshi Chakraborty Dept Of electrical engineering, Guru Nanak Institute of Technology, Kolkata, India, "New Approach OF A Conceptual Solar Therma Steam Generator and its Design \& Optimization". 
[5] J.K Kishore, Senior Scientist, ISRO, jkk40@yahoo.com, "Can existing thermal power plants be upgraded as integrated solar-coal hybrid thermal power plants for green power generation- A national challenge".

[6] B.Zeroul 1, A.Moummi 2,Department of engineering of materials university of Dr. Yahia Fares Medea, Algeria,Laboratoire de Genie Mecanique(LGM) University Mohamed Khider Biskra, Algeria, "Design of Parabolic Trough Collector Solar Field for Future Solar Thermal Power Plants in Alger2012 $2^{\text {nd }}$ International Symposium on Environment-Friendly Energies and Applications.

\section{ABOUT AUTHORS}
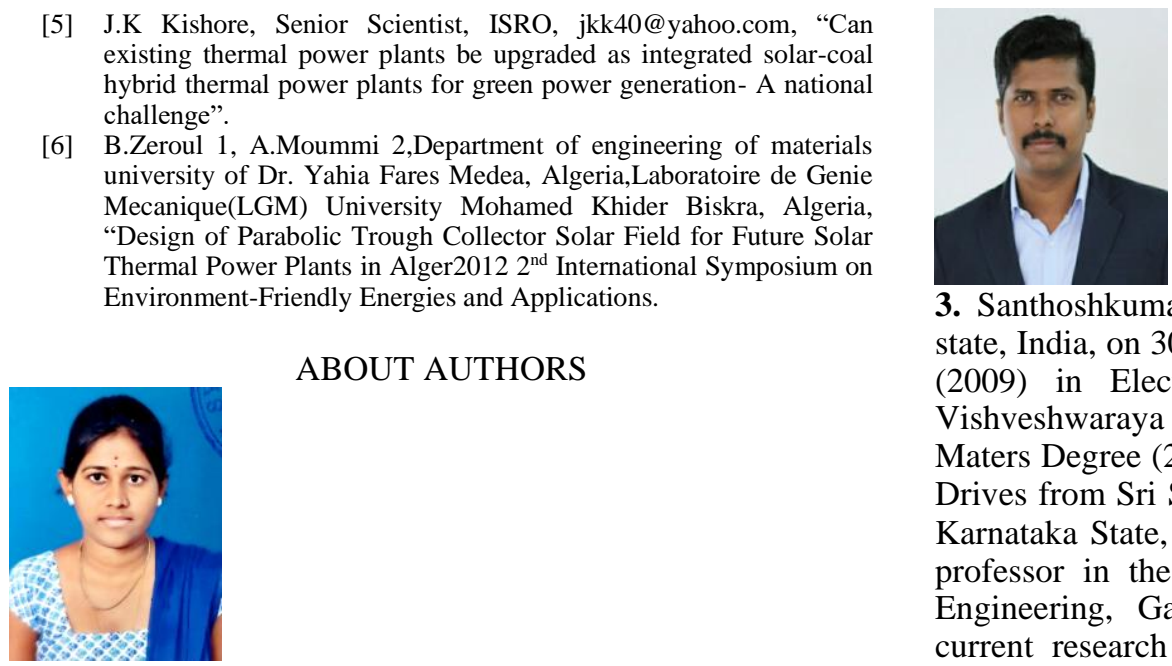

3. Santhoshkumar G.M was bron in Davangere, Karnataka state, India, on $30^{\text {th }}$ January, 1985 . He received a B.E. Degree (2009) in Electrical and Electronics Engineering from Vishveshwaraya Technological University, Belagavi and Maters Degree (2012) in Computer Applications in Industrial Drives from Sri Siddhartha Institute of Technology, Tumkur, Karnataka State, India. Currently he is working as Assistant professor in the Department of Electrical and Electronics Engineering, Gadag district, Karnataka state, India. His current research interests include power Electronics, High voltage engineering and power electronics for renewable energy resources. He has published many international and national papers. His membership includes International Association of Engineers (IAENG), The Institution of Engineers (IEI). affiliated to Vishveshwaraya Technological University, Belagavi. She is interested in power generation and transmission and distribution system.

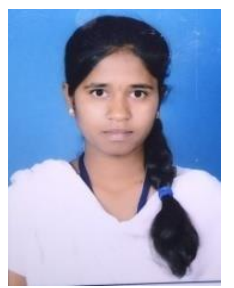

2. Roopashree Mulimani was born in Alnavar Town, Dharwad, Karnataka state, India, on $14^{\text {th }}$ October 1998. Now pursuing B.E. $\left(4^{\text {rd }}\right.$ year $)$ in Electrical and Electronics Engineering, Tontadarya College of Engineering, Gadag, affiliated to Vishveshwarya Technological University, Belagavi. She is interested in Power electronics, Electric power generation and Digital system design, 3D Animation and Artificial Intelligence. She has published a paper in International Journal. 